\title{
A PROPOSED TRAINING PROGRAM FOR THE PIONEERS OF THE COPTIC MUSEUM AS A STARTING POINT FOR ESTABLISHING CULTURAL IDENTITY BY ESTABLISHING A SMALL PRODUCTION PROJECT IN THE FIELD OF METAL FORMATION
}

\author{
Hind Khalaf Morsi MOHAMED *
}

Artistic Works and Folklore Department, Faculty of Art Education, Helwan University, Egypt.

\begin{abstract}
Faculty of Art Education - Helwan University The issue of rooting cultural identity is one of the important issues for the development and advancement of peoples and the advancement of mankind and society from all cultural, intellectual, scientific and political aspects, and also as a fundamental factor in shaping human behaviour, in light of the expanding technological advancement that made man open to multiple cultures In the world at the local, regional and international levels, and since the various community institutions seek to qualify the human cadres to become productive and not only consumable, and from here begins the starting point that depends on the training of cadres, provided that this is in some handicraft artistic crafts by establishing a small productive project for them, then This matter should not separate the individual from his historical and political roots in light of the rooting of his cultural identity to make his project distinct. Keywords

Political Roots; Handicraft; Heritage; rehabilitation; UNESCO; Drawings.
\end{abstract}

\section{Introduction}

The cultural identity is the true criterion by which the true value of a people can be measured, and this identity is formed because of the interaction of many factors, the most important of which are intellectual and religious beliefs, as well as historical and environmental factors. Therefore, cultural identity has multiple and interrelated dimensions, foremost of which are religion and language, in an integration that reflects the thought and philosophy of a society.

Many community-based institutions seek to promote the heritage and traditional handicrafts at the local level through associations that call for the preservation of heritage and crafts or through regional and Arab organizations that call for this, represented by the Arab Organization for Education, Science and Culture that helps to advance artistic crafts and also at the level The international organization represented by UNESCO, which works to revitalize and advance some handicrafts in the form of small industries.

From this standpoint, it is necessary to think about how to find starting points to guide trainees and practitioners of art in this direction. Moreover, in view of the tremendous development in the industrial field, which threatens many artistic heritage industries with extinction, which at that time were technical industries with lesser value. Therefore, before starting to present any model for a small production project, it must be based on sound scientific foundations and its operation in order to ensure its success and achieve the desired goal.

From this standpoint, the researcher believes that it is necessary to submit a proposal for a training program in the field of mineral formation to root the cultural identity of the visitors of the Coptic Museum to establish a small production project. This program aims to prepare a trainee (as one of the human cadres and they are the pioneers of the Coptic Museum) in order to be a productive and effective member in The development of society, especially in the economic field, and accordingly, this group of non-specialized and inexperienced - in the field of art in general and in the field of mineral formation in particular - can be directed towards these projects so that the trainee becomes a producer for them through a small productive project.

This is within the framework of rooting the trainee's cultural identity through his study of Coptic art, during field visits and simulations of Coptic drawings that carry many symbols with intellectual, philosophical and ideological connotations, which have a great impact on the trainees. Those who follow some handicraft metal crafts in Egypt find that there are some small industries that are close to disappearing despite their artistic wealth, for many reasons, including the economic factor and the high prices of raw materials and tools in addition to the importation of metalwork at the lowest prices.

* Corresponding author: art_education@helwan.com 
Many countries rely on small productive projects to increase their national product as a focus of development. Therefore, these countries were keen to present educational and training plans, programs and curricula for them through good planning and preparation in rehabilitating training workshops with actual practices on the ground while providing financial support for their success.

Through the researcher's practical vision in this field, he found that this type of small or micro enterprises related to areas that need skills, as is the case in their connection to the field of manual metal forming with its different methods and techniques, can contribute to solving the problem of many trainees to eliminate unemployment and raise their level In addition to that, it can be one of the sources of foreign exchange income, and it also contributes to the development of the skill and technical capabilities of the participants in these projects so that they are qualified and support them in their quantitative and qualitative production.

Perhaps one of the reasons for the researcher to conduct a proposed training program for the pioneers of the Coptic Museum as a starting point for establishing a cultural identity to establish a small productive project in the field of mineral formation is what she noticed while training for artistic workshops in the field of metal forming within the Coptic Museum School, which is that the visitors to the museum are of different professions as well as the same.

Different age groups also, and all of them seek to learn how to shape the metal ore, but it has been observed that they strive to obtain the acquired information related to the plastic style of the technique used by the metalwork, and it was also noted that the pioneers from different social segments and all of them seek to raise their economic level and are often characterized The metalwork carried out by them is far from aesthetic features and our original Egyptian culture and heritage.

Therefore, the researcher found that it is possible, through the development of a proposed training program for Coptic Museum visitors, to establish the cultural identity to establish a small productive project in the field of mineral formation. In this study, the researcher emphasized the necessity of providing a heritage artistic input to be a starting point for achieving designs based on the uniqueness of its production and the inability to repeat it because of this uniqueness of raising aesthetic values.

This has the greatest impact on the individual's acquisition of a unique artistic work, which has a positive impact on the success of the project. From this standpoint, the researcher has tended to benefit from the aesthetic values of Coptic art by studying its symbols and artistic elements in the work of a distinctive metal product that is contemporary and in line with the social, cultural and intellectual changes in society in order to meet the needs of community members as part of the implementation of the training program proposed to be implemented within the Coptic Museum School. To achieve the above, the researcher found that there are some requirements that must be met in the proposed training program, namely:

- Training the visitors of the Coptic Museum on how to make use of Coptic art with its symbols (decorative elements) in making new designs for the production of metalwork with aesthetic values commensurate with the general taste of the community members and emphasizing the cultural identity.

- Training the visitors of the Coptic Museum on the metal plastic plasticizing methods described in the training program in line with the nature of the requirements of the proposed training program in terms of quality in the implementation and final finishing of the product.

- Training the visitors of the Coptic Museum on how to link the skillful and aesthetic aspects of the product to be implemented so that both of them complement the other, so that the trainee does not turn into a mere craftsman who performs only, and also so that what he produces does not turn into industrial practices that do not rise to what the program aims to prepare The personality of the trainee in being an innovator aware of aesthetic values and an connoisseur of Coptic art.

\section{Research Problem}

Can cultural identity be rooted by setting up a small production project in the field of mineral formation through a proposed training program for Coptic Museum visitors? Research aims:

- Rooting the cultural identity of the Coptic Museum visitors to set up a small production project through a proposed training program in the field of mineral formation.

- Contributing to the service of the external community and the development of humankind and the environment by training some of the pioneers of the Coptic Museum to achieve an opportunity to increase their economic return.

- Employing the field of metalworking, through the proposed training program, in solving the problem of unemployment in light of the rooting of the cultural identity of some of the visitors of the Coptic Museum and helping them to set up a small production project.

\section{The Concept of Cultural Identity and Its Levels}

A brief study of Coptic art and its associated expressive symbols and connotations related to intellectual, philosophical and ideological beliefs. 


\section{A PROPOSED TRAINING PROGRAM FOR THE PIONEERS OF THE COPTIC MUSEUM AS A STARTING POINT FOR ESTABLISHING CULTURAL IDENTITY BY ESTABLISHING A SMALL PRODUCTION PROJECT IN THE FIELD OF METAL FORMATION}

\section{The Concept of Cultural Identity}

Culture means, in its broadest sense, "the sum of the spiritual, material, intellectual and emotional features that characterize a particular community or a particular social group and it includes the arts, literature, ways of life and economic production as well as the basic rights of the human being, value systems, traditions and beliefs. As for the term identity, it means absolute truth, which includes the facts include the nucleus on the tree in the absolute unseen.

The word identity is used in contemporary literature to fulfill the meaning of the word "Identite", which expresses the characteristic of conformity: matching the thing to itself, or its identity with its counterpart. Cultural identity is known in the English language (cultural identily), which is a group of cultural characteristics that distinguish a group of people from others, and it is also known as a system consisting of many values and customs agreed upon by a group of individuals that reflect the prevailing culture in the society in which they live. Cultural identity is one of the cultural terms that combine sociology and human culture, which refers to all events in which individuals within their society are affected and become part of their culture over time.

Therefore, cultural identity contributes to reflecting the nature of a society and how to accept or reject ideas, and this is what leads to identifying the degree of its influence related to external factors, which depends on the cultures of other societies. The meaning of cultural identity is defined, as "identity basically meaning individuality and cultural identity is cultural uniqueness with all that the meaning of culture includes in terms of habits, patterns of behavior, inclination and outlook on the universe and life.

Measuring the true value of a people, and this identity is formed because of the interaction of many factors, the most important of which are intellectual and religious beliefs, as well as historical and environmental factors. Based on this concept, it is not an exaggeration to say that it is one of the most important challenges facing the countries of the world, especially developing countries. Therefore, cultural identity has interconnected and interconnected dimensions, foremost of which are religion and language, in an integration that reflects the thought and philosophy of a society.

\section{Levels of Cultural Identity}

the cultural identity is distributed on a group of levels, which are as follows: The individual level: also known as the individual identity, which refers to the culture of each member of society in his personal capacity, meaning that one individual reflects the prevailing culture in the society in which he is present. Within a single group, whether it is a family, tribe, association or other groups, it is one of the distinct and independent elements that contribute to influencing the prevailing culture, directly or indirectly. The collective level: known as the collective identity, which is related to the influence of a group of individuals who represent a particular group on the dominant cultural identity in the society in which they are located. They are considered as individuals within the same group and are seen as one element characterized by the cultural identity of the society.

The national level: also known as the national identity, which combines the individual identity and the collective identity in one group. It is the main component of the cultural identity, which refers to individuals and groups within the same state. The national identity is also keen to promote social coexistence between individuals within the same society.

In this research, the researcher seeks to establish the cultural identity in the members of the external community, some of the pioneers of the Coptic Museum through their study of Coptic art with its symbols and expressive significance that the Coptic artist dealt with according to the intellectual, philosophical and ideological beliefs that are appropriate for the era in which he lives, and contribute to the service of the external community and the development Humanity and the environment by training some pioneers of the Coptic Museum (the research sample to achieve an opportunity to increase the economic return for them within the framework of establishing a small productive project in the field of mineral formation.

Museums in general play a vital role in achieving national harmony through cultural and intellectual unification between different classes of society. And in all parts of the country, which leads to the national cohesion of society, the affirmation of the national feeling, the national and national identity, the unification of the national identity, and the rooting of the cultural identity.

\section{Coptic Art}

Coptic art is one of the Egyptian arts that bear a distinct character that is characterized by many philosophical and doctrinal features, and which carried many meanings, ideas and beliefs expressing the thought and philosophy of the era in which the individual lives. This art contributed to raising the minds of the public and teaching them the Christian religion at the hands of individuals The Church, so the symbol had a clear role in Coptic art to express the Christian faith.

The Coptic artist was able to formulate his symbols represented in the decorative elements or units with his artistic works, so many of his artistic works appeared in multiple and different formulations, each according to the function he dealt with and the tools and materials through which he passed. Each decorative element of the 
Coptic artist had an expressive and symbolic significance related to the nature of his intellectual, philosophical and religious beliefs, so many decorative elements that the artist formulated in his works appeared to us, which were often such works to serve religious affairs.

The museum is a national investment and the nation's heritage, as it displays an artistic collection of human creations for the purpose of fun, study, research and revealing the human value in different eras. The museum also transfers the recipient from worlds whose time and place have passed, but they remain alive in the memory whose value increases day by day.

It is considered as an argument and a source for revealing these values. The primary goal of museums is the preservation of the heritage in its entirety, preservation and introduction to it, as they contribute to the completion of the necessary scientific studies with the aim of reaching an understanding and determination of the meaning and ownership of this heritage, and they help museums in general in the preparation of a global ethics based on practices With the aim of preserving, protecting and disseminating cultural heritage values. As for the educational mission of museums, despite their different nature, their scientific role is parallel in importance, which is no less than the role of other educational institutions such as schools and universities.

Most of the artworks showed the ingenuity of the Coptic artist in his formulation of the symbols that he addressed in his works, either by simulation, modification or abstraction, reflecting the philosophy of the era in which he lives, which was often merged with the philosophy of religious belief, as the Coptic symbols of the artist were different, whether animal or human.

On the other hand, botanical, geometric, or other - it is one of the most important ideological symbols as it carries expressive and symbolic connotations specific to the nature of the era in which the artist lives. Where symbolism is one of the most important characteristic of Coptic art, its inception is due to the political, social, and even cultural conditions of the pre-Christian period. It originated from the Egyptian popular culture, the artist crossed through symbolism to what he wanted to express indirectly, and the spread of symbolism in Coptic art began.

Since the second century, when the Coptic artist expressed the concepts of the Christian faith, especially the concepts of salvation and the aspiration to the kingdom, some Egyptian deities and some mythological subjects were used in their depiction, in addition to some symbols of birds, animals, fish, and some geometric shapes such as the circle and even the first sections of the sacred names and others. People with wide eyes, short, slender bodies, and large heads are an expression of the insightful vision.

8 Symbols in Coptic art have received great attention in many works of art, so they came out loaded with meanings, seriousness and symbolism related to the thought and philosophy of this art, so the symbol is considered a mere sign or an abstract shape with its connotations and meanings It transforms from an abstract form to a tangible form that has repercussions in the subconscious because the symbol is a product of mental culture and a concentrated abstract of thought. "Therefore, we find that a thousand Nan the Coptic sought to use it to craft symbols in many works of art such as weaving, ceramics, woodwork, metalwork and others.

Those who observe the symbols in Coptic art will find that the Coptic artist has reflected in his formulation many of the plastic and expressive values through his reliance on two important aspects to achieve the expressive aspect, namely the aesthetic aspect and the functional aspect. The aesthetic aspect is that aspect related to the artist's vision, thought and analysis of the forms of his symbols, which interact within him of feelings and emotions stemming from his thought and ideological philosophy through his symbols, which are a true translation of spiritual themes and similarities that have a direct relationship to the teachings of the Bible, which led to the emergence of Coptic symbols with a vision that reflects his ideas And his religious beliefs, seeking to present and publish a story or meanings related to religion.

As for the functional aspect, it is that aspect related to achieving the functional purpose of the executed worker, which carried on its surfaces Coptic symbols in a formulation that combines aesthetic and expressive values, using the materials and tools through which it is passed to achieve the functional purpose within the framework of the religious belief service. The artist was seeking to choose the technical methods that support the function and help to highlight the aesthetics of the design through the distribution of Coptic symbols.

Among the most important symbols formulated by the Coptic artist in Egypt, which have been affected by cultural and cultural heritage, human symbols, plant symbols, animal and birds symbols, marine organisms, reptiles and insects, various vocabulary of nature, geometric shapes, the symbolism of numbers and letters, as well as the symbolism of colors. In this research, the researcher will briefly present the symbolic significance of some polar symbols that will be covered by the trainees, the pioneers of the Coptic Museum, in the proposed program, and the investment of some of the Coptic symbols as an aesthetic investment in the design and implementation of a metalwork that corresponds to the proposed training program. The researcher will address the use of some plant symbols. In addition, animals, birds, geometric shapes, etc., for example, and not limited. 


\section{A PROPOSED TRAINING PROGRAM FOR THE PIONEERS OF THE COPTIC MUSEUM AS A STARTING POINT FOR ESTABLISHING CULTURAL IDENTITY BY ESTABLISHING A SMALL PRODUCTION PROJECT IN THE FIELD OF METAL FORMATION}

\section{Results}

- Contributing to the service and development of the members of the external community through training some of the pioneers of the Coptic Museum in light of the implementation of the proposed training program to achieve an opportunity to increase their economic return.

- Employing the field of metalworking through the application of the proposed training program in solving the problem of unemployment and in light of the rooting of the cultural identity of the Coptic Museum visitors, and assisting them in setting up a small productive project.

- $\quad$ Rooting the cultural identity of some members of the external community (the pioneers of the Coptic Museum) through their study of Coptic art with its symbols and expressive connotation that the Coptic artist dealt with in accordance with intellectual, philosophical and ideological beliefs.

- That the practice and experimentation by some of the pioneers of the Coptic Museum within the framework of the proposed training program in the field of mineral formation provides an opportunity to open a fertile field for the work of a small productive project.

- Developing the intellectual and skillful ability of the trainees to analyze, modify, abstract and simulate the symbols of Coptic art in various formulations through the design and implementation of metalwork.

\section{Recommendations}

- The researcher recommends the necessity of offering different training programs in the field of metal shaping that will benefit the external community.

- The researcher recommends the necessity to focus on scientific research through which it is possible to combine the formative and the functional side together in a way that benefits and opens the labor market to members of the external community to enrich the field of metalwork.

- The researcher recommends the necessity of rooting the cultural identity of the members of the external community through the study of art in general and the field of mineral formation in particular by setting up many training programs in the field that benefit the members of the external community on the cultural and economic level.

- The researcher recommends the necessity to study Coptic art in the field of metallic shaping, because of the symbolic connotations that this art includes related to the philosophy of the Christian faith.

\section{References}

1) Jalal Ahmad Abu Bakr, 2011 AD: Coptic Arts, The Anglo-Egyptian Library, Cairo.

2) Jalal Amin, 2001 AD: Globalization, Iqra Series, Third Edition, Dar Al Maaref.

3) Inayat Al-Mahdi, 1994 AD: "The Art of Metalworking and Goldsmithing, Ibn Sina Library, Cairo.

4) Suad Abdel-Fattah Abdel-Gawad 1990: The role of small industries in teaching and manufacturing, National Planning Institute, Cairo, Egypt.

5) Izzat Zaky Hamid Qadus, Muhammad Abd al-Fattah al-Sayyid, 2002 AD: Coptic Antiquities and Bez Antia, House of Knowledge University, Alexandria.

6) Nasser Al-Ansari, 2008 AD: Coptic Art in Egypt 2000 Years of Christianity, The Egyptian General Book Organization, Cairo.

7) Safia Al-Minshawi Al-Khouly, 2014 AD: Business Administration and Drug Marketing, Faculty of Commerce, Al-Azhar University, University Book House.

8) Nafisa Abdul Rahman Al-Afifi Abdel Aziz Al-Qawsy: Aesthetic Values for the Use of Threads and Mineral Ores and Their Role in Small Embroidered Industries, Unpublished PhD Thesis, Faculty of Home Economics, Helwan University.

9) Theses and Scientific Research:

10) Ibn Daoud al-Arabi Marbah, Abu Zayya Baya, 4/15/2010 AD: “The Problem of Cultural Identity and Cultural Globalization", published research, Journal of Human and Social Sciences, First International Forum (on identity and social fields in light of the sociocultural transformations in Algerian society, University of I mean profit.

11) Ahmed Hafez Hassan, 1985 AD: Benefiting from the artistic and technical values of Mamluk metalwork by a banker of innovative crafts, unpublished PhD thesis, Faculty of Art Education, Helwan University. 
12) Mr. Muhammad Al-Deeb, 4/21/2003 AD: Globalization and Cultural Identity, "published research, symposium (local cultures in the shadow of globalization), Institute of African Research and Studies, Department of Anthropology, Cairo University.

13) Hamid Al-Sayed Muhammad Al-Badrah, 1981 AD: The role of the popular blacksmithing craft in developing the formation of thin metal strips and the possibility of using them in teaching metalworking at the Faculty of Art Education, unpublished PhD thesis, Faculty of Art Education, Helwan University.

14) Hamid Al-Sayed Muhammad Al-Badrah, 1997: Aesthetic Values of Physical Surfaces of Minerals, a refereed research article by the Scientific Committee for the position of Professor, Faculty of Art Education, Helwan University.

15) Hamed Al-Sayed Muhammad Al-Badrah, April 2017: Aesthetics of Civil Formation by Cutting Between Concept and Application, Published Research, The Scientific Journal of the Emsia Society, Education Through Art, Issue 10.

16) Doaa Mansour Abu El-Maati, 2014 AD: Establishing productive projects for youth by employing textile printing, published research, International Scientific Conference, Faculty of Art Education, Helwan University.

17) Abd al-Rahman al-Nashar, 1972 AD: A Comparative Study of Symbolism in Painting and Children's Drawings, an unpublished Master Thesis, Faculty of Art Education, Helwan University.

18) Mary Mikhael Sakharoun, 2006 AD: Aesthetic Values of Ancient Egyptian Art in Forming Coptic Art Symbols, Unpublished Master Thesis, Faculty of Art Education, Helwan University.

19) websites :

20) Majd Khader, The Electronic Newspaper (Mawdoo3), last update 8:22), April 26, 2016 AD, last visit to the site October 14, 2017 AD, insist_cultural identity and its levels on http: // mawdoo3. com /

21) https://m.facebook.com/story.php?story_fbid=868026236686

22) https://st-takla.org/Gallery/Architecture/Christian-Places/Coptic-ArtArtifacts/Capital-Peacocks-Bawit.html

23) https://st-takla.org/Gallery/Architecture/Christian-Places/Coptic-ArtArtifacts/Peacock-Coptic-Museum.html

24) https://st-takla.org/Gallery/Architecture/Christian-Places/Coptic-ArtArtifacts/Eagle/Eagle-Coptic-Art1.html

Received: February 8, 2018

Accepted: April 16, 2018 